\title{
O DEBATE SOBRE IDENTIDADE, CULTURA E CONHECIMENTO EM UM PROGRAMA DE MESTRADO PROFISSIONAL EM EDUCAÇÃO DE JOVENS E ADULTOS: PROCESSOS FORMATIVOS PARA A DOCÊNCIA E PARA A EDUCAÇÃO DE JOVENS E ADULTOS
}

\author{
Maria Hermínia Lage Fernandes Laffin (UFSC)* \\ Audemara Rodrigues Vieira do Nascimento (UNEB)** \\ Antonio Amorim (UNEB)***
}

\begin{abstract}
RESUMO
O objetivo deste artigo é situar um ensaio mediante uma análise teórica acerca da relação entre identidade e cultura no contexto do conhecimento fundamental e formativo na Educação de Jovens e Adultos, no Programa de Mestrado Profissional em EJA. Para tanto, busca-se uma definição conceitual dos termos identidade e cultura, ao mesmo tempo em que se investiga a constituição da identidade cultural brasileira a partir da contribuição das matrizes étnicas presentes na história do Brasil, seguida de discussões sobre identidade, cultura e conhecimento na EJA no contexto atual. Este texto resulta de pesquisa bibliográfica e reflexões do aporte teórico de Munanga (2009), Sacristán (2006), Silva (2000) e Freire (1979), entre outros que discutem as múltiplas referências e a diversidade da identidade cultural dos sujeitos que frequentam a EJA e sua relação com o currículo. A análise teórica apresenta como resultado a necessidade do reconhecimento da diversidade cultural do povo brasileiro pela EJA. Discute, por fim, a proposição de uma escola aberta às múltiplas identidades presentes na escolarização na EJA e na formação docente.
\end{abstract}

Palavras-chave: Conhecimento. Cultura. EJA. Identidade. Formação docente.

\begin{abstract}
THE DEBATE ON IDENTITY, CULTURE AND KNOWLEDGE IN A PROFESSIONAL MASTER'S PROGRAM IN ADULT AND YOUTH EDUCATION: FORMATIVE PROCESSES FOR TEACHING AND FOR THE EDUCATION OF YOUNG PEOPLE AND ADULTS.

The purpose of this article is to situate an essay through a theoretical analysis of the relationship between identity and culture in the context of the fundamental knowledge
\end{abstract}

\footnotetext{
Professora do Curso de Pedagogia e do Programa de Pós-Graduação em Educação e da Universidade Federal de Santa Catarina (UFSC). Doutora em Educação pela Universidade Federal de Santa Catarina (UFSC). Pós-Doutora pela Universidade do Estado da Bahia (UNEB). Líder do Grupo de Pesquisa: Estudos e Pesquisas em Educação de Jovens e Adultos (EPEJA). E-mail: herminialaffin@gmail.com

** Professora da Educação Básica da Rede Municipal de Ensino de Barreiras. Mestranda do Programa de Pós-Graduação em Educação de Jovens e Adultos da Universidade do Estado da Bahia (MPEJA/UNEB). E-mail: arv.mara@bol.com.br

*** Professor Pleno do Departamento de Educação Campus I da Universidade do Estado da Bahia. Doutorado em Psicologia pela Universidade de Barcelona - Espanha. Líder do Grupo de Pesquisa: Gestão, Organização, Inovação e Políticas Públicas em Educação. E-mail: antonioamorim52@gmail.com
} 
and formation on adult and youth education, in the professional master's program in Adult and Youth Education. Therefore, it is sought a conceptual definition of the terms identity and culture, at the same time when is investigated the constitution of the Brazilian cultural identity from the contribution of ethnic matrices present in the history of Brazil, followed by discussions about identity, culture and knowledge in YAE in the current context. This text result of bibliographic research and reflections of the theoretical contribution of Munanga (2009), Sacristán (2006), Silva (2000) and Freire (1979), among others that discuss the multiple references and diversity of the cultural identity of the subjects that attend the YEA and its relation with the curriculum. The theorical analysis shows as result the necessity of the recognizing of cultural diversity of the brazilian people through the YAE. It discusses, finally, the proposal of a school open to the multiple identities present in the YEA schooling and in the teacher formation.

Keywords: Knowledge. Culture. YAE. Identity. Teacher formation.

\section{RESUMEN}

\section{EL DEBATE SOBRE LA IDENTIDAD, LA CULTURA Y EL CONOCIMIENTO EN UN PROGRAMA DE MAESTRÍA PROFESIONAL EN EDUCACIÓN DE JÓVENES $Y$ ADULTOS: PROCESOS FORMATIVOS PARA LA DOCENCIA Y PARA LA EDUCACIÒN DE JÓVENES Y ADULTOS}

O objetivo deste artigo é situar um ensaio mediante uma análise teórica acerca da relação entre identidade e da cultura no contexto do conhecimento fundamental e formativo na Educação de Jovens e Adultos, no Programa de Mestrado Profissional em EJA. Por lo tanto, se pretende una definición conceptual de la identidad y la cultura, al mismo tiempo que se investiga la constitución de la identidad cultural brasilera a partir de la contribución de matrices étnicas presentes en la história del Brasil, seguido de discusiones sobre identidad, la cultura y el conocimiento en la educación de jovenes y adultos en el contexto actual. Este texto resulta de investigaciòn bibliogràfica y reflexiones del aporte teórico de Munanga (2009), Sacristán (2006), Silva (2000) y Freire (1979) entre otros que discuten sobre las múltiples referencias y la diversidad de la identidad cultural de los sujetos que asisten a la EJA y su relación con el curriculo. El análisis teórico há dado lugar a la necesidad de reconocer la diversidad cultural del pueblo brasilero para la EJA. Se discute, por último, la propuesta de una escuela abierta a las múltiples identidades presentes en la escolarizaciòn en la educación de jovenes y adultos y la formación docente. Palabras claves: Conocimiento. Cultura. EJA. Identidad. Formación docente.

\section{Introdução}

Neste artigo apresenta-se um ensaio, no qual se problematiza a relação entre identidade, cultura e a Educação de Jovens e Adultos (EJA) no contexto de estudos desenvolvidos no Mestrado Profissional em Educação de Jovens e Adultos (MPEJA). Entende-se que um ensaio pressupõe um debate lógico e reflexivo mediante a análise, explicitação e interpretação de determinada problematização (SEVERINO, 2007), com o objetivo de situar inferências sobre ela, não dispensando um "cuidado" metodológico e epistemológico. Nesse contexto, é preciso lembrar que a problematização neste ensaio constitui-se: qual a importância desse debate e temática realizados em um curso de mestrado profissional?

Sua pertinência se situa no fato de que o curso em questão tem como objetivo principal a formação docente para a EJA e, desse modo, trazer o foco para essa formação à relação entre identidade social, cultura e processos educacionais. Apresentar este artigo nos permite, portanto, socializar a temática para pesquisadores e docentes em formação, 
como também apontá-la como possibilidade de intervenção em práticas pedagógicas mais humanizadoras e emancipadoras no âmbito da própria EJA, principalmente se consideramos que nossos estudantes jovens e adultos vivenciam muitas vezes processos de exclusão de suas próprias culturas que, geralmente, são silenciadas pela própria sociedade e escola.

Para esse debate, o presente texto resulta de uma pesquisa de abordagem qualitativa, que utilizou como instrumento a análise bibliográfica, a partir de autores e repositórios de pesquisa disponíveis na rede de computadores que discutem a temática. O objetivo é identificar contribuições teóricas acerca do entendimento da identidade e da cultura no contexto do conhecimento eleito como formativo para a EJA. Portanto, apresentam-se os conceitos de identidade na perspectiva de olhar os sujeitos como resultado das relações e da percepção de si, ou seja, que são seres em processo de construção e da cultura como produção dos homens na ação transformadora da natureza, como também o processo de formação da identidade do brasileiro a partir da contribuição das matrizes étnicas presentes na história do Brasil, com o intuito de trazer possibilidades para a compreensão e superação dos traços negativos na percepção do outro, ou dos diferentes nas relações entre os sujeitos. Por fim, pretende-se apresentar discussões sobre a relação entre identidade, cultura e conhecimento na EJA no contexto atual, considerando as transformações econômicas e sociais e, principalmente, o papel do conhecimento na formação dos jovens e adultos.

A identidade ou identificação dos indivíduos ocorre através de processos ao longo da vida nos diversos contextos em que a vivência cotidiana se realiza. Nessa perspectiva, a discussão acerca da identidade cultural e étnica dos sujeitos que frequentam a Educação de Jovens e Adultos, bem como da cultura, parece constituir temática relevante para pesquisa, considerando as práticas culturais e a identificação dos sujeitos como aspectos significativos na reflexão sobre o conhecimento proposto no currículo para a formação escolar do adulto.

O texto está organizado em quatro tópicos seguidos das considerações finais. O primeiro tópico situa o leitor na dinâmica metodológica utilizada na pesquisa e o segundo discute os conceitos de identidade, cultura e escolarização/formação, fundamentado em Munanga (2009), Sacristán (2006), Silva (2000), Freire (1979) e outros. No terceiro buscamos os argumentos para discorrer sobre a construção da ou das identidades do povo brasileiro, apresentando as matrizes étnicas que formam as bases para a identificação do povo brasileiro. Logo após, no quarto item, são apresentados pressupostos para pensar sobre os novos sujeitos da EJA no contexto da globalização e do reconhecimento da identidade e da cultura como aspectos promotores da ressignificação dos conhecimentos pelos estudantes, e trata principalmente da necessidade de reconhecimento da diversidade cultural do povo brasileiro pela EJA.

As abordagens da identidade e da cultura, bem como sua relação com a EJA, geralmente estão relacionadas às formas como as sociedades organizam sua produção econômica. Assim, considera-se que, no momento atual, em face da globalização, é preciso compreender a formação das identidades culturais na sua constituição histórica e contemporânea para a proposição dos conhecimentos na EJA. A partir da concepção que entende a cultura em sua dinamicidade, observar a constante produção de novos sujeitos integrados aos novos contextos que são feitos e refeitos no movimento de adaptação às condições da vida. Apresenta-se, por fim, a proposição de uma escola aberta às múltiplas identidades.

\section{Percurso metodológico da investigação}

Adotou-se neste ensaio a abordagem qualitativa de pesquisa que, segundo Lakatos e Marconi (1996), se trata de uma pesquisa que tem como premissa analisar e interpretar aspectos mais profundos, descrevendo a complexidade do comportamento humano. Assim, busca-se compreender o fenômeno em sua inteireza, mas, principalmente, conhecer as percepções dos sujeitos em suas abordagens.

A técnica instrumental usada foi a da pesquisa bibliográfica ou de fontes secundárias. Trata-se, segundo Gil (2008), de utilizar material construído por outros sobre um fato para a compreensão de um tema, principalmente livros ou artigos científicos. A construção teórica decorre quase sempre de pes- 
quisas, leituras, observação mais acurada dos fatos e também atividade de reflexão. Escrever sobre o produto das reflexões feitas por outros também requer compromisso responsável na interpretação das ideias alheias. Na pesquisa realizada, para fundamentar o processo reflexivo, foram utilizados autores que tratam de identidade, cultura e EJA. No caso deste texto caracterizar-se como um ensaio, a bibliografia é de grande relevância no aprofundamento dos estudos, pois possibilita conhecer as teorias estabelecidas sobre um tema ou fato, inclusive identificando as contradições. As referências provocaram indagações sobre como pensar a identidade e a cultura na EJA; a partir dai, buscaram-se na literatura pertinente fundamentos para discutir a questão.

A compreensão do homem como ser histórico, que constrói e se constrói ao produzir cultura, e de relações, que se constitui na relação com outros, faz pensar o conhecimento formativo na EJA na perspectiva da tradução e significação das práticas culturais das sociedades, bem como da ressignificação do conhecimento legitimado pelas ciências.

\section{Identidade e cultura}

A pergunta “quem sou eu?" poderia ser apresentada e múltiplas respostas poderiam ser elaboradas, a partir da perspectiva que se entendesse como relevante para um grupo social. São questões como gênero, raça, idade, filiação ideológica e religiosa, classe social e quantas mais forem acolhidas e validadas pelos coletivos sociais que constituem referências e símbolos representativos, povoam o imaginário dos indivíduos e os fazem aproximar-se formando uma unidade, ainda que temporária. A relação da identidade com as percepções da sociedade suscita o debate com a cultura, exigindo uma análise dos conceitos para melhor compreensão.

$\mathrm{Na}$ literatura, alguns aspectos aparecem como relevantes na construção da ou das identidades. As práticas desenvolvidas pelas sociedades humanas, valores e normas que dirigem as ações e são transmitidas às novas gerações, bem como a simbologia criada e apropriada nas trocas cotidianas, ou nos ritos sociais, são, sem dúvida, instrumentos que produzem os comportamentos e as crenças, conceitos que, a partir da apropriação de cada indivíduo, resultam nas identidades. Segundo Silva (2000, p. 14): “[...] o social e o simbólico referem-se a dois processos diferentes, mas cada um deles é necessário para a constituição das identidades."

A apropriação dos sentidos impregnados nos símbolos pelos coletivos vai resultar na construção da marca que identifica cada sujeito, porque, “[...] a marcação simbólica é o meio pelo qual damos sentido a práticas e a relações sociais" (SILVA, 2000 p. 14). Os grupos criam símbolos que trazem a ideia de unidade frente à diversidade comum entre os seres humanos; de certa forma as diferenças são minimizadas em nome de uma identificação com algo ou um posicionamento.

O nível psíquico também é importante para a formação da identidade, ou seja, a aceitação corrobora a afirmação de quem se é. Ainda na discussão acerca da constituição da identidade, entende-se que a história de um povo pode representar o elo para sua identificação no presente. Ou seja, diz Silva (2000, p. 27) que: "Ao afirmar uma determinada identidade, podemos buscar legitimá-la por referência a um suposto e autêntico passado." O passado comum, muitas vezes lembrado sem as contradições ou conflitos vivenciados, produz a acomodação dos espíritos na certeza de que há uma aproximação e, portanto, uma identidade que une os indivíduos, mesmo em sua diversidade. Pode-se até olhar a história do coletivo como um espelho para individualizar-se, ou identificar-se, no presente.

Castells (1999) esclarece que a identidade é um processo de construção, a partir de um atributo cultural, ou de um conjunto coerente de atributos culturais que recebe prioridade sobre as outras fontes. A identificação passa, pois, por vários caminhos e se constrói à medida que se constituem relações sociais, ocorrem marcações simbólicas, ou mesmo os sujeitos identificam-se em um passado comum. Ainda assim, diante dos acontecimentos alheios aos sujeitos, estes selecionam os aspectos relevantes na formação de suas identidades, à medida que aceitam ou rejeitam os atributos da cultura. Dessa forma, portanto, um mesmo indivíduo pode ter muitas identidades, o que tende a gerar contradições no seio da sociedade.

Os atributos valorizados marcam as diferenças em um coletivo. Tais características por um lado identificam, por outro excluem. As sociedades 
classificam os atributos e, para Silva (2000), essa classificação ocorre quando os membros de uma sociedade chegam a certo grau de consenso sobre como classificar as coisas a fim de manter alguma ordem social. Os aspectos considerados válidos são reconhecidos e quem os partilha ou possui ocupa lugar de destaque; já aqueles que não se adéquam, são rejeitados. Esses sistemas partilhados de significação são, na verdade, o que vai constituindo a identidade dos sujeitos.

Para compreender o conceito de identidade é importante esclarecer o que se entende por cultura. As primeiras percepções de cultura estavam associadas à ideia de civilização, consideravam-na como um atributo dos países com um grau de desenvolvimento mais avançado, na perspectiva dos europeus. Partia-se dos princípios evolucionistas em que os povos que habitavam as Américas, por exemplo, estavam classificados em um nível inferior na escala da evolução e, portanto, desprovidos de cultura. Esse entendimento justificava a dominação de um povo sobre outro. Após o século XIX, o termo passa a ser utilizado no plural, o que permitiu a compreensão de que não há uma, mas várias, isto é, cada povo passa a ser visto como único e sua cultura, singular, sendo assim inexplicável a hierarquia entre elas.

Os teóricos também definem cultura como a produção humana no decorrer do tempo, mas convém esclarecer duas vertentes que discorrem amiúde sobre a questão. Para o entendimento desse processo é necessário definir a que cultura se refere. Cultura pode ser definida como o conteúdo resultante da produção da ciência, humanidades e artes validadas historicamente pelas sociedades e transmitido, geralmente por meio da escrita, aos jovens como legado importante do seu passado. Com a transmissão desse material cultural busca-se o modelo de homem e mulher, não apenas para uma sociedade local, mas para a humanidade, independente do território no qual se estabelecem as nações. Ela é universalizadora e utilizada pela educação, pretende formar o homem sob uma nova natureza. Acessar esse capital cultural poderá permitir o desenvolvimento das sociedades, a partir do que foi historicamente construído pelos homens.

Laraia (2004, p. 54) traz a compreensão compartilhada nas teorias modernas sobre cultura como um sistema adaptativo. Situa que os teóricos modernos, apesar de divergirem, concordam que

Culturas são sistemas (de padrões de comportamento socialmente transmitidos) que servem para adaptar as comunidades humanas aos seus embasamentos biológicos. Esse modo de vida das comunidades inclui tecnologias e modos de organização econômica, padrões de estabelecimento, de agrupamento social e organização política, crenças e práticas religiosas, e assim por diante.

Na acepção antropológica surge, assim, um conceito de cultura que pode ser resumido ao conjunto de experiências ou tradições, modos de vida de um povo que os identifica. Nesse sentido, a cultura se territorializa e há uma demarcação social, formando vínculos e gerando pertencimento aos grupos, ou condicionando a agir depreciativamente em relação aos que não se encaixam nos padrões estabelecidos. Essa concepção pode gerar os laços que tanto acolhem como excluem os diferentes.

Paulo Freire (1979), entretanto, chama atenção para outro aspecto na compreensão da cultura, no sentido não de adaptação ou assimilação apenas, mas de reflexão e ação do homem sobre a natureza e o mundo ao seu redor. Ou seja, distingue cultura da reprodução de modelos dados, e associa à autoria, destaca que, a partir das relações que estabelece com seu mundo, o homem, criando, recriando, decidindo, dinamiza este mundo. Contribui com algo do qual ele é autor. Por esse fato cria cultura (FREIRE, 1979).

Identidade e cultura, portanto, adquirem significados a partir da perspectiva ou abordagem que se tome. São conceitos que advêm de visões de mundo e posicionamentos políticos. Pode-se considerar identidade no sentido universal, em que os aspectos coletivos prevalecem sobre os individuais, reduzindo os sujeitos a uma unidade, ou reconhecer as individualidades e, a partir daí, valorizar as diferenças e particularidades dos sujeitos. Também identificar a cultura como o resultado da produção intelectual consolidada de um povo considerado desenvolvido em relação a outro, pela posse de um capital cultural que prevalece sobre os demais. $\mathrm{Ou}$, em contrapartida, valorizar a produção dos diversos grupos e indivíduos, reconhecendo como cultura todo e qualquer produto resultante da ação humana na sua relação com o mundo. 
As críticas apresentadas à construção conceitual de cultura até o século XX exigem uma revisão do que se pensou até o momento. Busca-se a desconstrução dos conceitos que aprisionam as populações em estereótipos culturais e reduzem as identidades a modelos estabelecidos. Não se admite, por exemplo, dizer que há apenas uma identidade do brasileiro, como se todos os sujeitos fossem apenas um. Dessa forma, compreender os conceitos em suas diversas possibilidades e dinamicidade, os aspectos culturais e sociais dos seres humanos, observados em sua singularidade e pluralidade, em sua particularidade e universalidade, vão trazer as referências para compreender a formação identitária dos sujeitos brasileiros.

\section{Construção da identidade do povo brasileiro}

Na tentativa de compreender as particularidades e compreensão da identidade do brasileiro, busca-se caracterizar as aproximações e distanciamentos dos coletivos populares no processo histórico da formação do povo brasileiro. A presença da população indígena no território, antes da colonização pelos portugueses a partir do século $\mathrm{XV}$, demarca o início do processo de formação da(s) identidade(s) do brasileiro e, portanto, serve de ponto de partida para este estudo. A utilização da mão de obra do povo africano para o trabalho escravo promoveu outro momento importante, que se configura como referência para a constituição identitária do povo brasileiro. Finalmente, tem-se como referência importante a imigração europeia e asiática, que, em diversos momentos da história, foi intensa, trazendo pessoas e culturas diversas para o país. Sem a pretensão de uma exposição linear, na perspectiva temporal, é nesse contexto de aproximações voluntárias ou não que se pretende discorrer.

Jean Léry (1961) deixou informações importantes sobre os índios brasileiros do século XVI. A antropologia e a arqueologia são referências para as informações apresentadas pelo autor sobre aspectos relevantes da vida dos indígenas no Brasil. Fala, dentre outros, dos Tupinambás, que se destacaram devido ao contato mais próximo com o homem branco, e sobreviviam da caça, da pesca, da agricultura e do extrativismo, como também praticavam diversos rituais mágico-sagrados; e dos Uetacá, que não apresentavam boas relações com os brancos. Sobre esses índios, diz Léry (1961, p. 63), eram “[...] invencíveis nessa região, comedores de carne humana, como cães e lobos, e donos de uma linguagem que seus vizinhos não entendem, devem ter tidos entre os mais cruéis".

Ainda conforme Léry (1961), os europeus incorporaram-se, inicialmente, à vida das tribos, o que favoreceu o intercâmbio comercial entre brancos e índios. Dependiam das alianças com os indígenas para garantir a alimentação e segurança, especialmente enquanto a atividade econômica principal era o extrativismo. Com a substituição do extrativismo pela agricultura, a necessidade de terras e de mão de obra para a lavoura levou os portugueses a expulsar os índios de suas terras e escravizá-los. Os índios reagiram em um processo de resistência à dominação ou se submeteram aos portugueses através da ação cristianizadora implantada pelos padres jesuítas. Os índios que optaram por manter seu modo de vida migraram para o interior, para regiões pobres e inóspitas, pois, agindo dessa forma, tornaram possível a preservação da sua herança cultural, biológica e social. Contudo, dos cinco milhões iniciais, restam apenas 896.917 índios, hoje, no Brasil, segundo dados do Censo Demográfico de 2010 (INSTITUTO BRASILEIRO DE GEOGRAFIA E ESTATÍSTICA, 2016).

Vale ressaltar que a identificação dos indígenas pelo Censo deu-se com base nas pessoas que se declararam no quesito cor ou raça e para os residentes em terras indígenas que não se declararam, mas se consideram indígenas. Entre 1991 e 2000 foi possível identificar alterações significativas no número de pessoas que se identificavam indígenas, fato que não estava diretamente relacionado aos nascimentos observados no período, segundo a Fundação Nacional do Índio (FUNAI) ${ }^{1}$ e o IBGE

\footnotetext{
1 “A Fundação Nacional do Índio - FUNAI é o órgão indigenista oficial do Estado brasileiro. Criada por meio da Lei $\mathrm{n}^{\circ} 5.371$, de 5 de dezembro de 1967, vinculada ao Ministério da Justiça, é a coordenadora e principal executora da política indigenista do Governo Federal. Sua missão institucional é proteger e promover os direitos dos povos indígenas no Brasil. Cabe à FUNAI promover estudos de identificação e delimitação, demarcação, regularização fundiária e registro das terras tradicionalmente ocupadas pelos povos indígenas, além de monitorar e fiscalizar as terras indígenas. A FUNAI também coordena e implementa as políticas de proteção aos povos isolados e recém-contatados. É, ainda, seu papel promover políticas voltadas ao desenvolvimento sustentável das populações indígenas.
} 
(INSTITUTO BRASILEIRO DE GEOGRAFIA E ESTATÍSTICA, 2016). Há também dados que refletem o reconhecimento dos indígenas brasileiros como sujeitos de direito. Como os demais habitantes do país, se voltam para a organização de coletivos que lutam pela valorização da sua cultura e defesa de suas terras. Entretanto, pela fluidez das informações, os dados estão desatualizados, mas

[...] podemos afirmar que existem hoje mais de 150 organizações indígenas, com maior ou menor amplitude e solidez. Essa tendência de um contínuo aumento no número e tipos de organização teve um grande impulso a partir da Constituição de 1988, quando as comunidades e organizações indígenas passaram a ter um poder legal de atuar judicialmente em favor dos direitos das pessoas que representam. (SILVA, 2007, p. 378).

O que se percebe, através do número de índios e de organizações registrados nas últimas décadas, é um (auto)reconhecimento da identidade e dos direitos de reconhecimento dessa identidade e cultura indígenas pela população descendente dos primeiros habitantes do Brasil.

No processo de organização das atividades econômicas, a necessidade de mão de obra leva à escravização de parte da população africana que é trazida para o Brasil. A escravidão pode ser definida como um sistema de trabalho no qual o indivíduo (o escravo) é propriedade de outro, podendo ser vendido, doado, emprestado, alugado, hipotecado e confiscado.

Os primeiros registros de negros que chegaram ao Brasil como escravos datam de 1538. Eles eram capturados na África e trazidos à força para a América em condições miseráveis, morrendo durante a viagem pelo oceano atlântico. Os que sobreviviam eram separados daqueles que se aproximavam culturalmente e misturados aos de outras tribos para perderem os vínculos culturais. Povos da pele de pigmentação negra arrancados de sua terra natal foram trazidos para o Brasil e somente após um longo processo de luta pelo ideal abolicionista, décadas após a independência deste país, foram tomadas medidas para libertá-los. Diferentemen-

Nesse campo, a FUNAI promove ações de etnodesenvolvimento, conservação e a recuperação do meio ambiente nas terras indígenas, além de atuar no controle e mitigação de possíveis impactos ambientais decorrentes de interferências externas às terras indígenas." Disponível em: http://www.funai.gov.br/index.php/quem-somos te de outros povos que vieram voluntariamente, segundo Munanga (2012), os negros tiveram na cor da pele o objeto de representações negativas e construção de uma identidade negativa, interiorizada pelas próprias vítimas. Eles, contudo, não aceitaram passivamente a submissão. Outro aspecto que contribuiu para criar dificuldades na afirmação da identidade negra no Brasil foi à mestiçagem. Ainda segundo o autor, a formação da identidade negra no Brasil, dentro da proposta da formação da identidade nacional, assim como na França, foi resultado de um racismo universalista. Usou-se a mestiçagem cultural e a miscigenação para forjar a assimilação da cultura africana em nome de uma cultura considerada superior. Entretanto, “[...] a resistência dos povos dominados deu origem a uma cultura de resistência" (MUNANGA, 2012, p. 38)

Já a imigração para o Brasil de pessoas oriundas de países europeus ocorreu devido aos interesses econômicos. No caso de asiáticos, como os japoneses, este interesse estava relacionado ao acesso à terra, com grande parte da população composta por trabalhadores rurais. Em busca de trabalho na lavoura do café e na indústria crescente, principalmente em São Paulo, chegaram os alemães, que devido a conflitos políticos saem de suas terras; já os árabes e chineses, para trabalhar principalmente na construção civil e no comércio. Crise na Espanha e economia crescente no Brasil atraíram as famílias espanholas, principalmente para trabalhar nas lavouras de café, motivos também que estimularam a formação das maiores colônia de imigrantes no país: a italiana e a portuguesa.

Os primeiros indígenas do Brasil, os portugueses, que iniciaram a constituição e a formação do Estado brasileiro, os africanos, que foram trazidos para trabalhar como escravos, e outros imigrantes, na consolidação desse Estado, compuseram o "caldo" cultural da formação da identidade ou das identidades que predominam no território brasileiro. As relações construídas no processo de formação social, econômica e cultural do país contribuíram para a formação das identidades do povo que aqui viveu e que hoje vive.

As relações nem sempre pacíficas produziram compreensões marcadamente equivocadas nas acepções de valor atribuído, principalmente, à população de pele negra e indígena. Apesar do 
discurso que indica a existência de uma democracia racial no Brasil, a história é marcada durante séculos e ainda hoje por situações de preconceito e desrespeito aos indivíduos desses grupos sociais, resistindo às afirmações cientificas de declarações da inexistência de raça, pois na pele as questões de raça são marcadas. Conforme Munanga (2009, p. 7):

[...] se a raça não existe biologicamente, histórica e socialmente ela é dada, pois no passado e no presente ela produz e produziu vítimas. Apesar do racismo não ter mais fundamento científico, tal como no século XIX, e não se amparar hoje em nenhuma legitimidade racional, essa realidade social da raça que continua a passar pelos corpos das pessoas não pode ser ignorada.

Na perspectiva antropológica, todas as identidades são construídas a partir da história, geografia, biologia, entre outras produções humanas, mas também pela redefinição que as sociedades fazem desse material no seu lugar e no seu tempo. Segundo Castells (1999), são construídas nas relações de força, sendo legitimadas pelos dominantes, na resistência dos dominados ou, ainda, proposta como projeto pelos atores sociais que pretendem criar nova identidade. Tudo num constante movimento, sem que nenhuma origem se constitua em essência fora do contexto.

A ideia de humanidade apresentou-se em duas experiências, segundo Munanga (2006). A primeira corresponde a um humanismo moderno com valores universalistas e democráticos, segundo o qual existe uma natureza comum a todos os homens, garantindo-lhes os mesmos direitos. A segunda, surgida da crítica da primeira, como geradora de tirania com os povos que não se enquadravam nas afirmações universalistas, veio dizer que existe uma identidade humana, mas essa é sempre diversificada. Entre uma ou outra perspectiva cabe superá-las, propondo um universalismo a reelaborar com base em duas exigências: reconhecer o outro como um ser que não se reduz à determinação de uma sociedade e reconhecê-lo em sua individualidade.

A discussão sobre diversidade cultural está em evidência, pelo suposto vínculo entre reconhecimento e identidade, ou seja, a percepção que as pessoas têm de si, ou dos outros. O reconhecimento, o não reconhecimento e ainda o reconhecimento negativo dos outros podem definir a percepção ou a identidade das pessoas e isso pode causar prejuízos; ser diferente pode representar a não aceitação em determinados contextos.

No processo histórico de constituição da "identidade" do brasileiro, predominou, na perspectiva do sociólogo Gilberto Freyre (1998), a mestiçagem resultante dos encontros entre os diversos grupos étnicos presentes no Brasil. A mestiçagem teria produzido no Brasil a chamada democracia racial, uma sociedade sem conflitos resultantes das relações entre os grupos étnicos na formação da identidade do brasileiro. Kabengele Munanga (2009) nega a mestiçagem na construção da identidade nacional. Diz que os grupos negro e índio produzem identidades diversas e não mestiças. Considera artificial a busca por uma alma nacional, isso porque as culturas estão em constante transformação.

É nessa perspectiva que se procura entender e discutir a Educação de Jovens e Adultos, a partir do reconhecimento das múltiplas referências e manifestações da identidade e diversidade cultural dos sujeitos que frequentam a escola.

\section{Identidade, cultura e EJA no contexto de um Mestrado Profissional}

O processo de organização das cidades demonstra o novo momento da sociedade no contexto da globalização. A grande diversificação social e cultural torna-se a marca registrada dos aglomerados urbanos, seja das metrópoles, seja das médias e pequenas cidades. Até mesmo em bairros localizados nas periferias das cidades tem-se a representação dessa característica da formação social, resultante do processo de globalização. São novas identidades que, na aproximação com o outro, com o diferente, são formadas no contexto da complexidade, onde se misturam as tradições às inovações, 0

local ao global, a juventude à experiência da idade adulta, o periférico ao central, entre outras condições. Este sujeito deverá ser educado para aceitar, enfrentar ou transformar esse novo mundo que se apresenta interligado, globalizado. Talvez seja esse o objetivo da educação de jovens e adultos, identificar os sujeitos, os espaços-tempos, ou territorialidades nos quais são constituídos e, a partir daí, pensar o conhecimento necessário à 
sua formação. Ou seja, em vez de preservar uma tradição monocultural, a escola está sendo chamada a lidar com a pluralidade de culturas, reconhecer os diferentes sujeitos socioculturais presentes em seu contexto, abrir espaços para a manifestação e valorização das diferenças (MOREIRA; CANDAU, 2007).

No processo de globalização, as relações econômicas, trocas culturais e rapidez na comunicação fazem pensar num processo econômico e social que estabelece uma integração entre os países e as pessoas de todo o mundo. Isso leva à ideia de possibilidades diversas de conexões em um mundo em que as relações são facilitadas e os encontros estimulados. Entretanto, nada é tão simples, pois vivemos em uma sociedade que envolve interesses econômicos e relações de poder, e nesse mundo globalizado contamos também com contradições e "[...] outras considerações determinantes, históricas, geopolíticas e econômicas. A cultura é importante para dar consciência a mal-estares, infligir danos, desvalorizar os outros, sentir-se superior a outros; para justificar e preparar a ação" (SACRISTÁN, 2006, p. 45). Assim, requer que seja lançado um olhar crítico, a fim de evitar definições aligeiradas sobre a situação representada no mundo globalizado.

Em princípio parece haver grandes possibilidades de integração econômica, da informação e dos espaços no processo em que se constitui a nova "aldeia global". Entretanto, são frágeis os resultados advindos dessa nova condição da sociedade internacional. Como alerta Milton Santos (2000, p. 29-30), a globalização está se impondo como uma fábrica de perversidades, "[...] O desemprego é algo tornado comum. [...] o ideal de democracia plena é substituído pela construção de uma democracia de mercado". As trocas existem entre os países, contudo dividem mais do que aproximam os povos e aprofundam as diferenças sociais, pois ocorrem numa competição desigual em que as condições são impostas pelos que possuem capital financeiro. Interessa, portanto, compreender o contexto gerado pelas novas relações econômicas capitalistas. São as relações de trabalho, o acesso à informação e ao conhecimento, as trocas culturais em nível global que interferem e se impõem diretamente na formação das identidades dos sujeitos localmente reco- nhecidos. Formam-se territorialidades identificadas por contextos mistos que provocam mudanças nas práticas sociais, incluindo a educação.

A socialização do conhecimento, apesar das aproximações, dá-se de maneira parcial, quando constatado um grande número de analfabetos ainda existentes no Brasil e principalmente no Nordeste brasileiro. São jovens e adultos que, inseridos em uma sociedade letrada, não participam democraticamente dos processos sociais. Observa-se um coletivo que, apesar do acesso tardio em vista do analfabetismo funcional, ${ }^{2}$ pouco utiliza o conhecimento em seu benefício. Torna-se um jovem e adulto que, inserido no mundo da informação, se vê alijado desse mecanismo de desenvolvimento e busca na educação formal uma ponte para o acesso a esse universo do saber. As demandas empreendidas pelos novos sujeitos que buscam a EJA exigem uma escola que reconheça esse homem ou mulher que busca a educação escolar.

O contexto da globalização instalado pelo capitalismo produz novos territórios e sujeitos que frequentam as classes da Educação de Jovens e Adultos. A reorganização no mundo do trabalho exige novos desafios, o acesso ao conhecimento requer habilidades interpretativas, os contextos socioculturais demandam formação para o reconhecimento e respeito às diversidades. Por isso a importância de refletir sobre a identidade e a cultura num Programa de Mestrado Profissional em Educação de Jovens e Adultos, para aprofundar o processo de construção dos saberes dos mestrandos e dos docentes nessa área de conhecimento, para ampliação e aprofundamento da formação em EJA.

Refletindo sobre essa realidade, destaca-se o que indica Sacristán (2006), que se apresenta à educa-

2 Segundo Ribeiro (1997, p. 147), “A ampla disseminação do termo analfabetismo funcional em âmbito mundial deveu-se basicamente à ação da Unesco, que adotou o termo na definição de alfabetização que propôs, em 1978, visando padronizar as estatísticas educacionais e influenciar as políticas educativas dos países-membros. A definição de alfabetização que a Unesco propusera em 1958 fazia referência à capacidade de ler compreensivamente ou escrever um enunciado curto e simples relacionado à sua vida diária. Vinte anos depois, a mesma Unesco proporia outra definição, qualificando a alfabetização de funcional quando suficiente para que os indivíduos possam inserir-se adequadamente em seu meio, sendo capazes de desempenhar tarefas em que a leitura, a escrita e o cálculo são demandados para seu próprio desenvolvimento e para o desenvolvimento de sua comunidade." 
ção o desafio de preparar para não se sabe muito bem o quê, uma vez que se ignoram quais saberes serão rentáveis no futuro dos sujeitos. Dessa forma, há que se pensar na construção do currículo, ou seja, a definição dos conhecimentos abordados na escolarização formal, com base no entendimento de que cultura promova o desenvolvimento dos coletivos humanos, já que a escola se constitui num importante instrumento de organização da sociedade. Pois, segundo Sacristán (2006, p. 55):

[...] os processos de globalização afetam a educação porque incidem sobre os sujeitos, os conteúdos do currículo e as formas de aprender. O conceito e a demarcação do que se vem entendendo por cultura nas escolas, na nova configuração do mundo, devem ser ampliados para que todos se sintam incluídos.

As transformações geradas pelos processos econômicos promovem a movimentação de pessoas e de capital, provocando novas relações culturais e formando, se é possível afirmar, novos sujeitos e, talvez, novos espaços. São identidades formadas nos conflitos, nos contatos com o diferente, que “[...] produz identidades plurais, mas também identidades contestadas, em um processo que é caracterizado por grandes desigualdades" (SILVA, 2000, p. 21). A escola ainda é um lugar onde principalmente os jovens e adultos podem adquirir instrumentos para atuar e transformar os espaços organizados na perspectiva capitalista, contribuindo para minimizar os seus efeitos negativos. A instabilidade na oferta de emprego ou mesmo as exigências de especialização tornam a educação formal, na percepção de muitos educadores e alguns responsáveis pela elaboração de políticas públicas, uma necessidade. Contudo, pretende-se uma educação para além da inserção no mercado.

É preciso que a educação esteja - em seu conteúdo, em seus programas e em seus métodos - adaptada ao fim que se persegue: permitir ao homem chegar a ser sujeito, construir-se como pessoa, transformar o mundo, estabelecer com os outros homens relações de reciprocidade, fazer a cultura e a história (FREIRE, 1979).

Os sujeitos que procuram e estudam na EJA, apesar de em alguns casos perceberem o papel da escola, na maioria das vezes seus projetos de sobrevivência falam mais alto e acabam se ausentando da escola. Ainda é preciso considerar que nem sempre a escola os tenha compreendido para propor um conhecimento e práticas que lhes interessem, e modos de organização dos tempos escolares que possam ser mais adequados às suas vidas cotidianas, haja vista os altos índices de evasão observados nessa modalidade de educação. Então, a quem interessa o conhecimento ensinado na escola? Como fazer a educação cumprir o papel de formar os sujeitos para o seu espaço e para o seu tempo? De que forma essa escola pode tomar o reconhecimento das identidades e a valorização efetiva das múltiplas referências culturais e que se tenha como eixo principal o fazer concreto daqueles que estão ali para aprender? Para pensar essas indagações e proposições, outras reflexões são necessárias, inclusive no âmbito do Mestrado Profissional em Educação de Jovens e Adultos, para pensar a formação do educador.

\section{Considerações finais}

Afinal, qual a relação entre identidade, cultura e EJA em um Mestrado Profissional nessa modalidade de Ensino? As contribuições teóricas identificadas nos permitiram uma imersão nos aspectos relacionados à cultura e à identidade dos sujeitos de EJA como elementos fundamentais. Nesta análise, ficam em evidência concepções diferenciadas acerca do conceito de cultura e identidade, mas observa-se a convergência em torno da necessidade de considerar a identidade dos sujeitos, de suas práticas culturais e dos processos de aproximação e de exclusão na formação da identidade dos indivíduos como eixos de estudo, como proposição para a Educação de Jovens e Adultos.

As matrizes étnicas e suas práticas culturais, que compõem a base referencial para a identidade ou as identidades observadas na atualidade, são por vezes colocadas em uma hierarquia de valor. As múltiplas referências étnicas na constituição da(s) identidade(s) no Brasil, bem como nessas hierarquias pré-estabelecidas historicamente entre os diversos grupos que compõem a nação, têm se manifestado na organização curricular e na proposição do conhecimento formativo da EJA. Nesse processo, os aspectos identitários e culturais de um grupo prevalecem e representam hegemonicamente a nação. No caso do Brasil, o branco europeu 
assume esse papel reconhecendo, por exemplo, a religião católica, a língua portuguesa e as ciências como práticas institucionais e validadas socialmente. À escola cabe divulgar e transmitir conhecimentos produzidos por este grupo, ou promover o debate e dar voz às diversas manifestações, como têm sido orientadas a partir da Lei de Diretrizes e Bases $n^{\circ}$ 9.394/1996 e dos diferentes documentos curriculares nacionais para a Educação Básica que incorporam os debates sobre culturas e etnias.

A identidade ou identidades do brasileiro formado nos encontros entre indígenas, africanos, europeus e populações que migraram de vários lugares do mundo para o Brasil, no decorrer da história, bem como os sujeitos que, na atualidade, sofrem os efeitos dos processos de globalização, nos aspectos: econômico e cultural, estão representadas no espaço escolar. A população jovem e adulta que frequenta a EJA representa esses coletivos, mas estão à margem do desenvolvimento econômico ou estão relegadas às periferias dos processos culturais. Os conhecimentos, portanto, que lhe são apresentados são produzidos por outros, segundo os interesses de outros, na linguagem de outros e assim direcionados a outros, ou seja, não lhes dizem respeito. Assim, indígenas, afrodescendentes, migrantes que estão às margens das conquistas econômicas, e que, por isso, não concluíram os estudos, ou ainda necessitam dos conhecimentos escolares para conquistarem sua afirmação social, fazem parte da EJA.

As identidades são constituídas nos encontros e desencontros que resultam das construções simbólicas produzidas pela cultura. Dessa forma, não se justificam as concepções arbitrárias e deterministas que isolam os diferentes e, no contexto educacional, fazem prevalecer determinadas concepções de conhecimento sobre outras, principalmente no contexto da EJA, que historicamente tem recebido um público oriundo dos grupos étnicos que não estão enquadrados como hegemônicos. Há que se aprofundar o processo reflexivo em torno dessas questões, pois elas são cruciais para fazer prevalecer a qualidade formativa nas classes da EJA. É papel da universidade preocupar-se com a identidade e a cultura da população, principalmente quando se trata de compreender e de efetivar políticas públicas que vão proporcionar a efetivação de aprendizagens complexas, que são oriundas de uma sociedade multicultural, como é a sociedade brasileira.

Importa, portanto, reconhecer criticamente os diferentes interesses subjacentes às escolhas efetuadas na formulação dos currículos escolares e de formação docente no que se referem aos interesses econômicos presentes nas sociedades e perpetuados pela escola, e a valorização da cultura de determinadas sociedade e sujeitos universais idealizados, à revelia das múltiplas manifestações culturais existentes nas mais diversas regiões do Brasil.

A produção teórica consultada convida à reflexão crítica, pois a abertura para o mundo pode apresentar-se como antídoto aos posicionamentos inflexíveis, excludentes e preconceituosos dos agentes educacionais e da sociedade, particularmente no contexto político nacional atual, até muitas vezes contraditório em relação à valorização das diferentes culturas e diferentes modos de viver. Desse modo, são necessários caminhos na busca do reconhecimento cultural, da valorização das individualidades para o estabelecimento de direitos e da construção de uma escola para jovens e adultos que, diante de um povo com origens múltiplas, possa evitar estereótipos e acolher a pluralidade, tendo em vista a convivência em um mundo diferente, porém menos desigual.

\section{REFERÊNCIAS}

CASTELLS, Manuel. O poder da identidade. A era da informação: economia, sociedade e cultura. Volume II. Lisboa: Fundação Calouste Gulbenkian, 2007.

FREIRE, Paulo. Conscientização, teoria e prática da libertação: uma introdução ao pensamento de Paulo Freire. São Paulo: Cortez \& Moraes, 1979.

FREYRE, Gilberto. Casa grande \& senzala. Rio de Janeiro: Record, 1998.

GIL, Antonio Carlos. Como elaborar projetos de pesquisa. 4. ed. São Paulo: Atlas, 2008. 
INSTITUTO BRASILEIRO DE GEOGRAFIA E ESTATÍSTICA (IBGE). Pesquisa Nacional por Amostra de Domicílios (PNAD) 2009. Brasília, DF, 2016.

LAKATOS, Eva Maria; MARCONI, Marina de Andrade. Técnicas de pesquisa: planejamento e execução de pesquisas, amostragens e técnicas de pesquisas, elaboração, análise e interpretação de dados. 3. ed. São Paulo: Atlas, 1996.

LARAIA, Roque de Barros. Cultura: um conceito antropológico. 17. ed. Rio de Janeiro: Zahar, 2004.

LÉRY, Jean. Viagem à terra do Brasil. Tradução de Sergio Milliet. Rio de Janeiro: Editora Biblioteca do Exército, 1961.

MOREIRA, Antônio Flávio Barbosa; CANDAU, Vera Maria. Indagações sobre currículo: currículo, conhecimento e cultura. Brasília, DF: Ministério da Educação/Secretaria de Educação Básica, 2007.

MUNANGA, Kabengele. Algumas considerações sobre "raça", ação afirmativa e identidade negra no Brasil. Revista da USP, São Paulo, n. 68, p. 46-57, fev. 2006.

Kabengele Munanga responde a Demétrio Magnoli. 2009. Disponível em: $<$ http://www.geledes.org.br/ kabengele-munanga-responde-a-demetrio-magnoli/>. Acesso em: jul. 2016.

Diversidade, identidade, etnicidade e cidadania. 2012. Disponível em: $<\mathrm{http}: / / \mathrm{www}$.acaoeducativa.org.

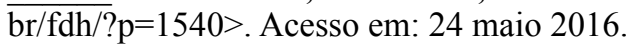

SACRISTÁN, José Gimeno. O significado e a função da educação na sociedade e na cultura globalizadas. In: GARCIA, Regina Leite; MOREIRA, Antonio Flavio Barbosa (Org.). Currículo na contemporaneidade: incertezas e desafios. 2. ed. São Paulo: Cortez, 2006. p. 41-80.

SANTOS, Milton. Por uma outra globalização: do pensamento único à consciência universal. 8. ed. Rio de Janeiro. São Paulo: Record, 2008.

SEVERINO, Antônio Joaquim. Metodologia do trabalho científico. 23. ed. São Paulo: Cortez, 2007.

RIBEIRO, Vera Masagão. Alfabetismo funcional: referências conceituais e metodológicas para a pesquisa. Educação e Sociedade, Campinas, SP, v. 18, n. 60, p. 144-158, dez. 1997.

SILVA, Rosa Helena Dias da. Movimentos indígenas no Brasil e questão educativa: relações de autonomia, escola e construção de cidadanias. In: FÁVERO, Osmar; IRELAND, Timoty (Org.). Educação como exercício de diversidade. Brasília, DF: Ministério da Educação, 2007. p. 371-400.

SILVA, Tomaz T. Identidade e diferença: a perspectiva dos estudos culturais. Petrópolis, RJ: Vozes, 2000.

Recebido em: 20/07/2016

Aprovado em: 09/10/2017 